\title{
New advances in the laboratory characterization of refractories: testing and modelling
}

\author{
Jacques Poirier ${ }^{1, *}$, Eric Blond ${ }^{2}$, Emmanuel de Bilbao ${ }^{1}$, Rudy Michel ${ }^{1}$, Antoine Coulon ${ }^{1}$, Jean Gillibert ${ }^{2}$, \\ Michel Boussuge ${ }^{3}$, Yang Zhang ${ }^{3}$, David Ryckelynk ${ }^{3}$, Gilles Dusserre ${ }^{4}$, Thierry Cutard $^{4}$, and Paul Leplay ${ }^{5}$ \\ ${ }^{1}$ CEMHTI, CNRS UPR3079/Université d'Orléans, 1D avenue de la Recherche Scientifique, 45071 Orléans cedex 2, France \\ 2 PRISME EA4229, INSA CVL/Université d'Orléans, 8 rue L.-de-Vinci, 45072 Orléans, France \\ ${ }^{3}$ Centre des Matériaux-Mines Paristech, CNRS UMR 7633, 63-65 rue Henry-Desbrueres, 91003 Evry cedex, France \\ ${ }^{4}$ Institut Clément Ader (ICA), Université de Toulouse, CNRS, Mines Albi, UPS, INSA, ISAE-SUPAERO, Campus Jarlard, \\ 81013 Albi CT cedex 09, France \\ ${ }^{5}$ Saint-Gobain, Centre de Recherches et d'Études Européen,550 avenue Alphonse-Jauffret, 84300 Cavaillon, France
}

Received: 18 July 2017 / Received in final form: 29 August 2017 / Accepted: 1 September 2017

\begin{abstract}
This publication presents new advances in the field of refractories characterization. These laboratory methods that combine experiments and numerical analyses and concern both the thermomechanical and thermochemical behaviour are illustrated through different examples: identification of asymmetrical creep, determination of elastic and inelastic properties, measurements of macroscopic deformation, phase transformations or corrosion kinetics. These advanced techniques offer the refractory community new opportunities to improve the knowledge and the prediction of the phenomena of degradation of the refractories.
\end{abstract}

Keywords: refractories / advanced characterization / optical methods / in situ experiments / modelling

\section{Introduction}

Refractory ceramics, which are used at high temperatures, in particular in metallurgical processes, must be selected according to the environment they will be exposed to. The refractories must withstand not only high temperatures but also thermochemical and thermomechanical stresses that influence their operational performances. The mastery of their behaviour and phase changes, which occur during use, is essential to ensure their sustainability. The numerical prediction of the behaviour and lifetime of industrial structures in application requires the ability to measure and identify the constitutive laws of the refractory materials used. This step may represent a real experimental challenge, which depends on the constitutive law to be identified. In most cases, in addition to the fundamental aspects and industrial appraisals, laboratory characterization methods provide essential additional information, which helps guide the choice of refractories, to determine the parameters governing the damages, to interpret damages based on theoretical data, understand the mechanisms and propose optimization of the formulations of the microstructures or lining design.

\footnotetext{
* Email: jacques.poirier@univ-orleans.fr
}

Knowledge of the refractories' characteristics involves the availability of a full range of laboratory analysis resources and requires in-depth expertise. The specificity of these refractory laboratory tests lies in the complexity of the numerous associated phenomena (thermal properties, chemistry, mechanics, etc.) and the experimental difficulties that are related to the use of high temperatures. Major advances have been made in the field of laboratory experiments and their interpretations in the last 10 years. These developments concern both the thermomechanical and thermochemical behaviour.

The thermomechanical behaviour of refractories is characterized by a dissymmetry of behaviour between tension and compression, non-linear and inelastic properties. This behaviour can be explained mainly by three mechanisms: damages, which appear at low temperature, stress relaxation, which is often due to the flow of vitreous phases at high temperatures, chemical or phase changeinduced stresses/strains [1]. This strong influence of the thermochemistry evolution of the material is one of the key points to understand their complex thermomechanical behaviour. A second key point is the damage ability of concrete-like materials.

Refractories are not inert materials. Since the properties of refractories are largely determined by intrinsic properties and microstructures, an understanding of phase transformations is essential. A phase transformation occurs 
when one refractory changes its composition or structure. The transformation can be caused by a change in temperature, or it may involve corrosion reactions.

Phase transformation includes local atomic mobility, transformation kinetics, heterogeneous reactions, diffusional transformations and microstructural changes.

The combination of high-performance experimental techniques with powerful numerical tools and high-speed computing makes it possible to access information that has been inaccessible via traditional direct measurements. In addition, multi-physical and multi-scale modelling tools provide support for a better understanding of the results of laboratory tests. The strong coupling between experiments and numerical simulation, which has been achieved in the last 10 years in the refractory field, leads to a deeper understanding of the behaviour of refractories and the identification of parameters concerning the materials and/ or processes, which enable them to extend the refractory lifetime.

This contribution presents original laboratory tests and associated numerical tools developed to characterize thermomechanical and/or thermochemical behaviour of refractories and details of in situ characterization techniques that are used to access microstructural and structural evolutions over time. Three major advances in the laboratory characterizations of refractories will be address in this publication through different laboratory developments (testing and modelling): optical methods, thermochemo-mechanic behaviour models and new in situ instrumentations and spectroscopies. After the introduction, this paper is divided into three parts:

- section 2 (Optical methods): The main important evolution in the experimental field of mechanics in the last 15 years is the development of optical measurements at room temperature. The potential of these optical methods, which have been used at high temperature for few years, is illustrated through three cases: the measurement and identification of asymmetrical creep via Digital Image Correlation (DIC); the determination of elastic and inelastic properties at high temperature via integrated Digital Image Correlation (i-DIC); hightemperature measurements of macroscopic deformation induced by phase changes;

- section 3 (Contribution of modelling to the interpretation of lab tests): The complexity of interpretation of the results of mechanical characterization (i.e., tensile test, bending) in the refractory field is linked to the strong thermochemical evolution of the specimen during the test. The contribution of numerical modelling and simulation for the interpretation of lab tests is illustrated via the case of the thermomechanical behaviour of fused refractories that exhibit strong induced effects of the tetragonal to monoclinic transformation of zirconia;

- section 4 (New insitu instrumentation and spectroscopies): These advanced experimental techniques facilitate the understanding of mechanisms and address the major problems of reactional kinetics: thermochemical reactivity, phase change, and corrosion. Two techniques are addressed that highlight the different mechanisms of phase transformation and show the practical importance of these phase transformations in the corrosion of refractories. The first example is the use of Raman spectroscopy and in situ high-temperature X-ray diffraction to study the phase transformations of Olivine. The second example concerns the use of time-resolved in situ high temperature X-ray diffraction to study the corrosion kinetics of high alumina refractories.

\section{Contribution of optical measurements for the characterization of refractories}

The main difficulty of high-temperature mechanical characterization is the measurement of strain. Indeed, classical strain gauges are not suitable for temperatures higher than a few $100^{\circ} \mathrm{C}$. An external extensometer coupled with alumina rod always induces artefacts and permits to access only the average strain due to homogeneity assumption on the extensometer length. Laser extensometers are interesting, but they are also subject to artefacts that are linked to radiation and convection. Therefore, to be able to measure the local strain from room temperature (RT) up to $1500^{\circ} \mathrm{C}$, optical measurement seems to be a promising approach.

The techniques of field measurement overcome the problem of global measures and local effects. The two advantages of the full-field measurement via optical set up are the absence of contact with the specimen and the ability to measure a field, not a global or local value, which an extensometer or a gauge allows. However, to be able to measure the strain of refractories using Digital Image Correlation (DIC), several challenges exist: quality of imaging at high temperature (between $1000{ }^{\circ} \mathrm{C}$ and $1500{ }^{\circ} \mathrm{C}$ for refractories), accuracy of DIC for very small strain levels (down to $10^{-5}$ ).

It is the combination of these two key points (high temperature and low strain) that makes this measurement a real challenge. In literature, several studies exist for DIC at high temperature $[2,3]$. However, in all cases, either the temperature is only approximately $600-800{ }^{\circ} \mathrm{C}$ (before the image quality is degraded using radiation) or the level of strain is high (approximately $10^{-1}$ or $10^{-2}$ ) so that the ratio of signal/noise is very favourable for DIC. This paper summarizes the different experimental and numerical developments for overcoming this challenge.

\subsection{Determination of elastic and inelastic properties at high temperature via I-DIC}

\subsubsection{Experimental set up}

The diametric compression of a disc leads to compression stresses along the vertical axis and tensile stresses in the perpendicular direction. Currently, this non-homogeneous displacement field is a rich source for mechanical characterization. Indeed, the coupling between DIC and numerical simulation permits further post-processing of data obtained from this test. For example, for a brittle material with a lower tensile strength than compressive strength, the failure results from the extension, and the crack is along the axis of solicitation. The maximal load before failure and geometry allows the direct estimation of the tensile strength, while the recording of the complete 


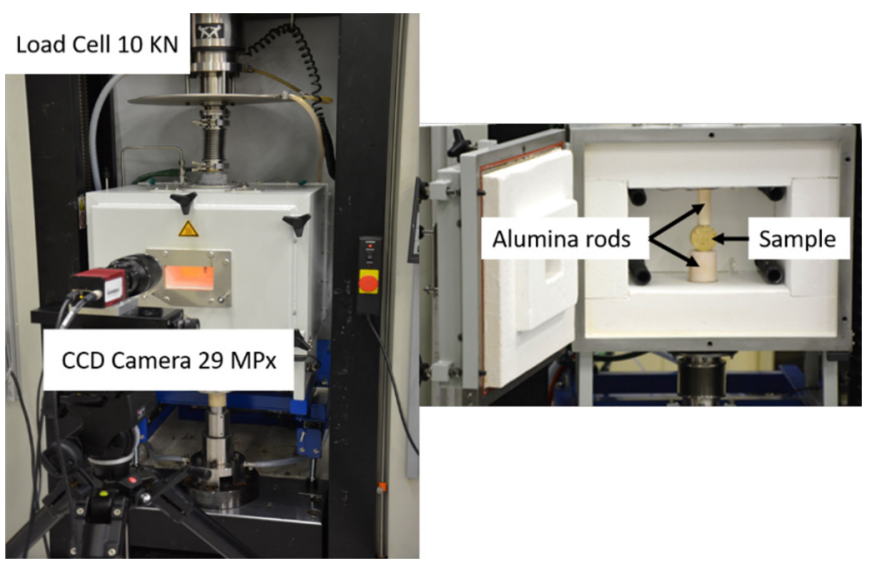

Fig. 1. Experimental set-up for mechanical testing at high temperature.

displacement field allows characterization of both tensile and compressive behaviours. An extension to creep study is also suitable.

The surface of the sample is observed using a CCD camera (Fig. 1). The maximum resolution of this camera is 29 megapixels, with a 14 bit digitization for grey levels. The maximum acquisition frequency is five images per second. To perform DIC, it is necessary to realize a random pattern. The material used for the random pattern must stick perfectly to the sample and be stable from RT to high temperature. Sometimes, the material microstructure constitutes a reasonable pattern, but it must not change during the test.

\subsubsection{Integrated Digital Image Correlation}

Full-field measurement techniques are more frequently used in the mechanical field to analyse the mechanical behaviour of a material and to study the real test conditions and their effects (i.e., boundary conditions) [4-6]. In classical DIC (often denoted as "local"), the picture is discretized in a small zone of interest, which is registered in the reference configuration. The algorithm looks for these zones after deformation to deduce the displacements fields. This method allows a sub-pixel precision and is recognized to measure strain of $10^{-4}$ [7]. This is sufficient to study metal but seems too rough to consider ceramic strain on the order of $10^{-5}$ to $10^{-6}$. As seen in Figure 2, considering only one large zone enhances the accuracy. This is why the fullfield measurement is preferred here.

Then, the main difference between the "integrated" DIC and classical full-field measurement methods is that the goal is no longer to measure the displacements fields or to estimate the strain fields but to directly identify the material parameters. Whatever the material's behaviour is, the material parameters are the values that must be incorporated into the model to be able to predict the effect of thermomechanical solicitations. It can be a simple model (purely linear elastic) or a complex one (with creep, damage, etc.). The first step still has to make an assumption on the behaviour that will be validated or not, depending on the results performed by the identification.

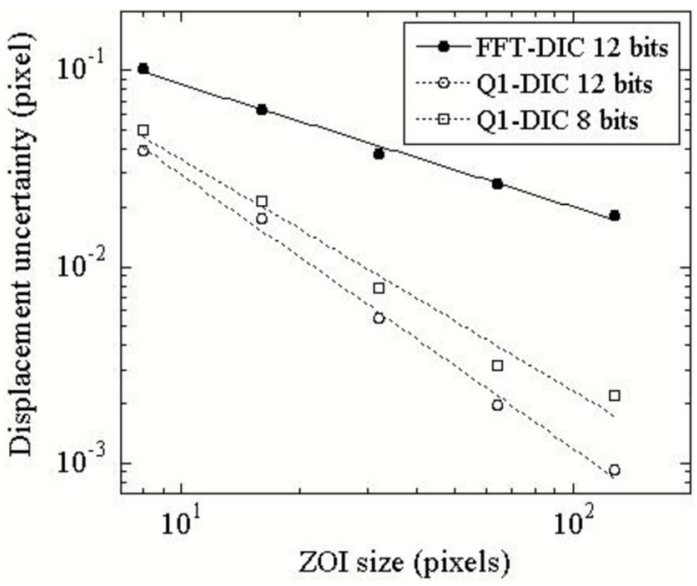

Fig. 2. Influence of the size of ZOI on the displacement uncertainty [HIL06].

The developed method is based on the DigImCo algorithm proposed by M. François [8]. In this algorithm, the correlation accounts for an a priori knowledge of the displacement field to reduce the admissible displacement fields to find the solution for the problem. It is the classical approach of "model reduction", which is often used to reduce the computational time. Here, the main advantage is that it permits bypassing many artefacts and enhancing the accuracy [7]. Then, it becomes essential to bear in mind that the goal is no longer to measure the strain or displacement but to identify the (material) parameters that permit to fit the a priori admissible displacements fields to the experimental data to obtain the best displacements fields that are in agreement with the initial assumptions.

In the proposed method which is illustrated in Figure 3, the a priori knowledge of the displacement field results from the assumptions on both the behaviour of the material and the experimental device. Then, the mechanical problem that corresponds to the experimental test will be solved, analytically or numerically, to define the relationship between the load and theoretical displacement field. In the next stage, using a reference image of the nondeformed sample, a series of theoretical images are created by applying the previously obtained theoretical displacement fields. Then, the comparison between the theoretical deformed image and the experimental one corresponds to the correlation step: the correlation is performed between the experimental and theoretical images. The results of the correlation provide a quantification of the gap between the theoretical and experimental displacement fields. Assuming that the choice of the behaviour law is correct and that the boundary conditions are accurate, the only source of discrepancy is the material parameters. Then, using an optimization algorithm, the material parameters that permit the best fit between experimental and theoretical displacement field are identified.

This method was successfully used to identify the Young's modulus and the Poisson ratio of an ITM membrane at high temperature [9]. This was performed using an analytical solution of the test, as described in [10]. For non-linear behaviour, it is necessary to use numerical computations to obtain the admissible kinematic field. 


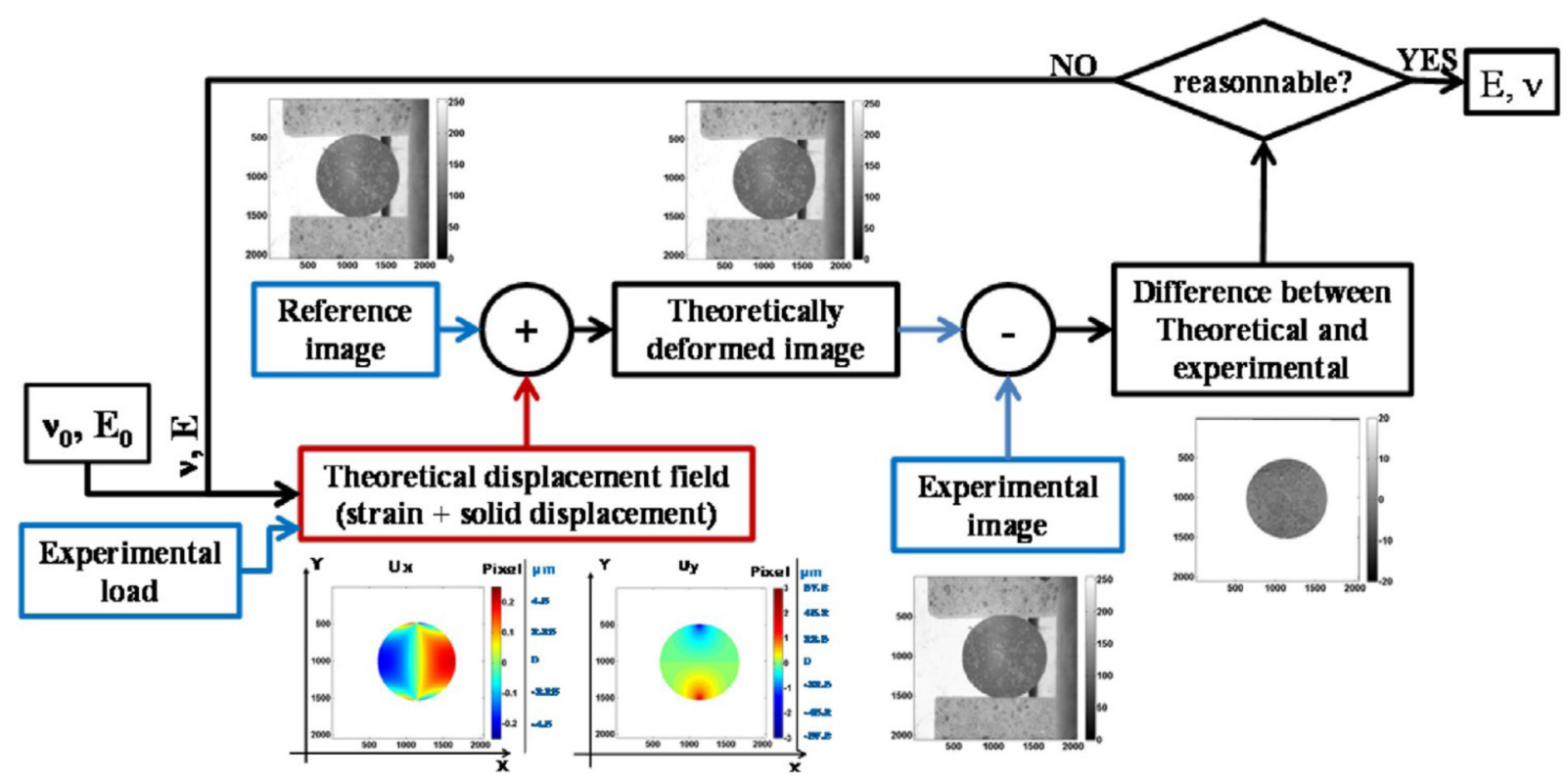

Fig. 3. Description of the algorithm used for the identification of mechanical properties.

Table 1. Result of the identification procedure.

\begin{tabular}{lllll}
\hline & \multicolumn{2}{c}{ Elastic properties } & \multicolumn{1}{c}{ Creep properties } \\
\hline & $E$ & $v$ & $A$ & $n$ \\
Known parameters & 91223.4 & 0.26 & $15.5 \times 10^{-12}$ & 1 \\
Identify parameters & 94492.5 & 0.22 & $14.6 \times 10^{-12}$ & 0.91 \\
Relative error & $3.57 \%$ & $11.64 \%$ & $5.47 \%$ & $8.65 \%$ \\
\hline
\end{tabular}

Then, the numerical method (often Finite Elements Methods) may be one more source of discrepancy. To quantify the noise induced by the numerical kinematic field, instead of an analytical approach, theoretical images were used. The Norton creep law was considered (Eq. (1)).

$$
\dot{\varepsilon}=A \sigma^{n} .
$$

A different set of initial parameters, non-equal to that used to create the "numerical experimental image", was used to initialize the identification loop. The results of this trial are presented in the Table 1.

The relative error can be explained by different factors. First, the rounding of the pixel value will generate a difference between the saved and generated images. To reduce the impact of this phenomenon, it is necessary to increase the size and encoding of the picture. Second, the loop output criterion can be changed to enhance the accuracy. Whatever the origin of the discrepancy, the relative error is reasonable. Thus, this trial allows the conclusion that these approaches can be used to identify material parameters for non-linear behaviour.

\subsection{Measurement and identification of asymmetrical creep via Digital Image Correlation}

Creep is prone to be asymmetrical between tension and compression because of the complex microstructure of refractory materials [11]. To identify such an asymmetrical creep law, one possibility is to separately run tensile and compressive uniaxial tests. However, this is often very complex at high temperature on ceramics [12]. A second possibility consists of running classical bending tests that are monitored via Digital Image Correlation to measure tensile and compressive creep rates in the same time [13] using reverse identification to obtain the uniaxial creep parameters [14]. This method requires dedicated experimental and numerical developments that will be presented hereafter.

\subsubsection{Experimental development for image quality at} $1350^{\circ} \mathrm{C}$

A parallelepiped sample $\left(15 \times 10 \times 150 \mathrm{~mm}^{3}\right)$ is tested in a four-point flexural device (outer span $\mathrm{D}_{1}=120 \mathrm{~mm}$, inner span $\mathrm{D}_{2}=40 \mathrm{~mm}$ ) with a dead load of $129 \mathrm{~N}$. The temperature is $1350^{\circ} \mathrm{C}$. In front of the furnace equipped with a sapphire window, a digital single-lens reflex camera is mounted. The camera is chosen for its large sensor size and high definition. One image is shot every $15 \mathrm{~min}$ for $45 \mathrm{~h}$. The physical size of the grey-level pixel is $16 \mu \mathrm{m}$. Three specific developments are performed to obtain high quality images that are suitable for DIC.

First, a paint pattern stable at $1350{ }^{\circ} \mathrm{C}$ for several days must be deposited on the sample surface. An in-house solution was developed with a non-oxide powder (silicon 


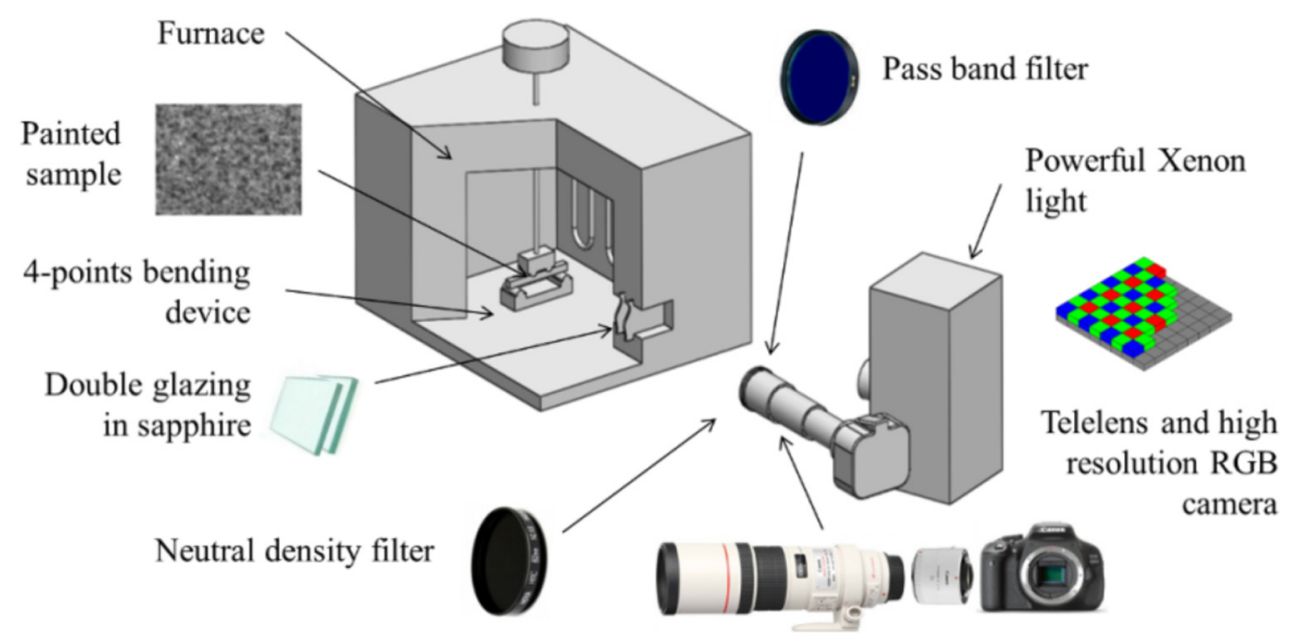

Fig. 4. Specific bench for creep monitoring via DIC.

carbide). The oxidation of this specific paint is slow enough so that the image contrast remains high during the entire creep test.

Second, radiation significantly increases beyond $900{ }^{\circ} \mathrm{C}$ so that classical RGB (Red, Green, and Blue) sensors are quickly saturated in red. One solution consists of adding powerful white lights so that the ratio between reflected light (for additional light) and emitted light (from radiation) becomes favourable for digital sensors despite the temperature. Please note that another solution consists of associating an additional blue light and a blue filter on the lens so that the light captured by the digital sensor becomes independent of radiation and temperature [3].

Third, a solution against heat haze must be found. Indeed, the natural convective movements of hot air inside the furnace generate a variation of the refraction index along the optical path between the sample and the lens. Since this variation is random with a high temporal frequency, a neutral density filter, which divides the quantity of light by 400 , is added to the lens so that the exposure time is lengthened up to $30 \mathrm{~s}$. Using this filter, we directly average the variations due to heat haze so that the DIC uncertainties are 10 times lower than in the initial configuration. With elements of width of $64 \times 64$ pixels, the standard strain uncertainty of DIC is approximately $0.4 \%$ for $1 / 250 \mathrm{~s}$ images and only $0.05 \%$ for $30 \mathrm{~s}$ images.

An overview of the developed experimental bench is given in Figure 4.

\subsubsection{Numerical development for the DIC accuracy at high temperature}

The image quality is excellent due to the previous experimental developments. The strain level to be measured remains small for DIC, as low as $10^{-4}$. Using a global finite-element formalism for DIC enables to be more accurate than for a local DIC that is based on FFT [13]. In both cases, the accuracy of DIC is directly dependent on the size of the chosen elements. However, the shape functions associated with each element are only bilinear (Q4 elements); thus, we cannot increase the element size too much without degrading the relevancy of the measured kinematic. An alternative is to use DIC with specific global shape functions depending on the kinematic to be measured [15]. In our case, for 4-point bending, the kinematic is analytically known according to the Bernoulli beam theory. Thus, a small number of global degrees of freedom is sufficient to describe the entire displacement field $u(x, y)$ on the sample [16]:

$$
\left\{\begin{array}{l}
u_{x}(x, y) \\
u_{y}(x, y)
\end{array}\right\}=\left[\begin{array}{ccccc}
-x y & -y & 0 & 1-x & x \\
\frac{x^{2}}{2} & x & 1 & 0 & 0
\end{array}\right]\left\{\begin{array}{l}
L^{2} \kappa \\
L \theta \\
\varpi \\
v_{0} \\
v_{1}
\end{array}\right\},
$$

where $L$ denotes the beam length, $\kappa$ is the constant curvature, $\theta$ is the rigid-body rotation and $\varpi$ is the vertical translation. Please note that in the horizontal direction, two degrees of freedom, $v_{0}$ and $v_{1}$, are needed to describe a rigid-body translation and enable a tension/compression asymmetry. As shown in Figure 5, the benefit is that the accuracy is improved since the number of degrees of freedom to measure is very small compared with the large number of available pixels. Now, the standard strain uncertainty of DIC is only approximately $0.007 \%$. In addition, the tensile and compressive strains are directly available without post processing.

\subsubsection{Example of the typical results}

By applying the previous experimental and numerical developments to the study of creep of a zirconium silicate product (ZS-ISO) that is fabricated by Saint-Gobain SEFPRO, the following typical results are obtained.

While the mean creep rate estimated from the classical vertical deflection measurement is approximately $1.66 \times 10^{-4} / \mathrm{h}$, DIC leads to a creep rate of $2.0 \times 10^{-4} / \mathrm{h}$ for tension and $1.35 \times 10^{-4} / \mathrm{h}$ for compression (Fig. 6). An asymmetrical ratio of approximately 1.5 is revealed between the tension and compression. It is also possible to calculate that the neutral axis has shifted by $+1.3 \mathrm{~mm}$ towards the top of the sample. 

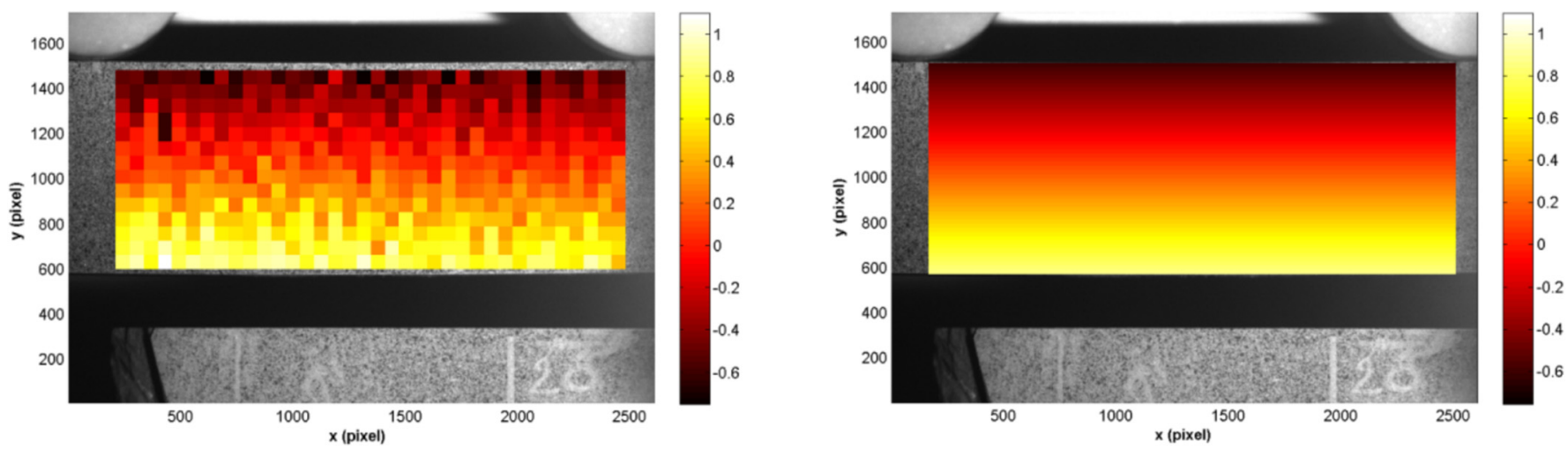

Fig. 5. Horizontal strain field after $45 \mathrm{~h}$ of creep. On the left, DIC with Q4 elements of $64 \times 64$ pixels; on the right, DIC with the global beam shape functions.

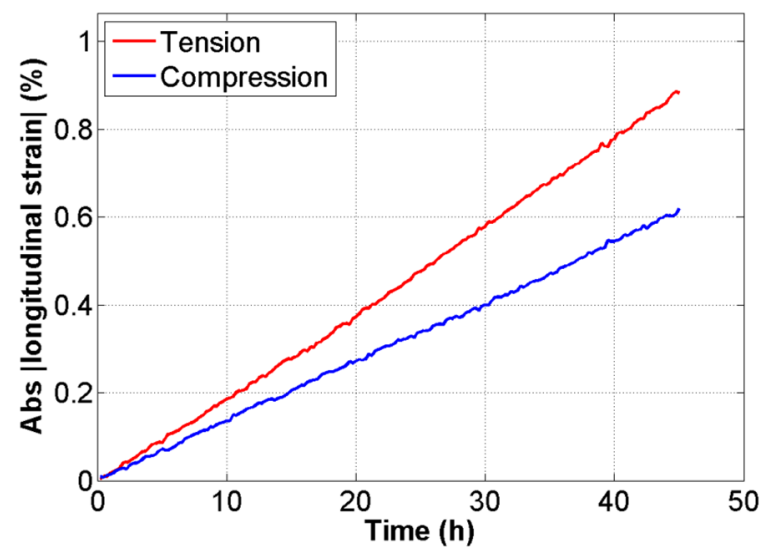

Fig. 6. Tensile and compressive strains during bending due to DIC.

This work has proven the feasibility of using DIC at high temperature to have access to unique information during conventional tests - bending tests in our case [14]. When this method has been applied to asymmetrical creep, it has been possible to reveal a difference in creep rates of 1.5 between tension and compression. Based on this field measurement, the next step consists of identifying the corresponding uniaxial parameters. This reverse identification of the constitutive laws for tensile creep and compressive creep will eventually enable to simulate numerically the full thermomechanical behaviour of refractory structures in application.

\subsection{Study of the asymmetric creep behaviour of a refractory concrete: experiment and modelling}

Modelling the in-use behaviour of refractory structures requires a suitable model that is able to describe the asymmetric creep as evidenced by the experiment $[11,14,17]$. In the case of refractory concrete, the variability inherent to the material necessitates to identify the parameters of the models for many samples and several processing and testing conditions. This section investigates the capability of the Drucker-Prager creep model to describe the behaviour of a fibre-reinforced refractory concrete. An identification procedure that requires only a few tests is proposed. The material is an ultra-low cement bauxite matrix that is reinforced with bauxite aggregates and 2 wt. $\%$ of FeCrAl fibres. It is described in $[17,18]$.

\subsubsection{Drucker-Prager creep model}

The Drucker-Prager creep model is based on the DruckerPrager yield criterion. It assumes that the creep rate is a function of an equivalent stress, $\bar{\sigma}^{c r}$, which depends on the Mises equivalent stress, $q$, and pressure $p$ :

$$
\bar{\sigma}^{c r}=\frac{q-p \tan \beta}{1-\frac{1}{3} \tan \beta} .
$$

The effect of pressure is parameterised by the friction angle $\beta$. In this work, the primary creep law was used to describe the behaviour of the material. The strain rate $\dot{\bar{\varepsilon}}^{c r}$ depends on the equivalent creep strain $\bar{\varepsilon}^{c r}$, which leads to the assumption of isotropic hardening of the material:

$$
\dot{\bar{\varepsilon}}^{c r}=\left[A\left(\bar{\sigma}^{c r}\right)^{n}\left[(m+1) \bar{\varepsilon}^{c r}\right]^{m}\right]^{\frac{1}{m+1}} .
$$

To avoid the singularity of the equivalent creep surface in the vicinity of $q=0$, a pseudo-potential $G^{c r}$ is used, which introduces the eccentricity parameter $\epsilon$ and the dilation angle $\psi$ :

$$
G^{c r}=\sqrt{\left(\in \cdot \bar{\sigma}_{0} \cdot \tan \psi\right)^{2}+q^{2}}-p \cdot \tan \psi
$$

The tensor of the creep strain increment is derived from this pseudo-potential, with $\Delta \varepsilon^{-c r}=\dot{\bar{\varepsilon}}^{c r} \Delta t$ :

$$
\Delta \frac{\underline{\underline{\varepsilon}}^{c r}=\Delta \bar{\varepsilon}^{c r}}{f^{c r}}\left(\frac{3}{2} \frac{\underline{\underline{S}}}{\sqrt{\left(\in \cdot \bar{\sigma}_{0} \cdot \tan \psi\right)^{2}+q^{2}}}+\frac{1}{3} \tan \psi \underline{\underline{I}}\right),
$$

$\bar{\sigma}_{0}$ is a homogenization parameter and has no influence in the present work. Therefore, the model is defined using six parameters, $A, m, n, \beta, \in$ and $\psi$, each related to a characteristic of the behaviour, except the eccentricity $\epsilon$, 
which is introduced to define a regular equivalent creep surface. $m$ defines the intensity of the hardening, $n$ is the stress exponent, $A$ is a multiplicative constant, $\beta$ controls the effect of $p$ on the creep intensity, and $\psi$ defines how the creep affects the spherical and deviatoric components of the strain increment.

The identification procedure, detailed in [17], assumes that eccentricity is very low, which means that the pseudopotential is almost linear, except for a very low deviatoric stress. Assuming a value of the dilation angle, this calibration method allows identification of the values of parameters $A, m, n$ and $\beta$ from only few compression tests and one bending test coupled with a kinematic full-field measurement.

\subsubsection{Calibration procedure}

In the first step, the experimental data, which are required to identify the parameters, are compression creep tests at a given temperature for several stress levels. These tests were performed using cylindrical specimens at $1200^{\circ} \mathrm{C}$ under 3 , 4, 5 and $6 \mathrm{MPa}$ of pressure between the alumina plates. A unidirectional model, which is based on the creep law described previously, allows to identify the parameters $m$ and $n$ by fitting the experimental time-creep strain curves. The value of the parameter $A$, which is also identified in this step, is not relevant because the equivalent stress was not introduced at this time.

In a second step, the procedure requires knowledge of the location of the neutral axis at the end of a bending creep experiment. In this work, this datum is obtained using a kinematic full-field measurement performed at room temperature after the interruption of the bending creep test at $1200^{\circ} \mathrm{C}$ [19]. This method is much easier to apply than monitoring the test at high temperature. However, more relevant results would be achieved by applying the method described in the previous section. A finite element simulation of this test allows computation of the neutral axis location as a function of parameter $\beta$. It has been proven [17] that the value of $A$ does not affect this result. For a given assumption about dilation angle the value of $\beta$ is thus identified to match the experimental neutral axis location.

The third step of the procedure involves a finite element simulation of the compression tests. The parameters $m, n$ and $\beta$ are set to their values, which were previously identified (assuming the dilation angle value), and the parameter $A$ is identified to fit the time-strain curves via the same approach as in the first step of the procedure but using the Drucker-Prager creep model instead of the unidirectional model.

The relevance of the compression test simulation strongly depends on its sensitivity to friction, which is subjected to uncertainty. To assess this sensitivity, friction tests were performed using a concrete pin with a spherical friction surface with a $25 \mathrm{~mm}$ radius and an alumina plane disk (normal load of $1 \mathrm{~N}$, i.e., $100 \mathrm{MPa}$ according to the Hertz theory, sliding velocity of $2 \mathrm{~mm} / \mathrm{s}$ ) at several temperatures. At $20^{\circ} \mathrm{C}$, a friction factor of approximately 0.3 was measured. At 600 and $790^{\circ} \mathrm{C}$, the friction factor reaches 0.6 . The device did not allow tests to be performed
Table 2. Parameters of the Drucker-Prager creep model for the refractory concrete at $1200^{\circ} \mathrm{C}$.

\begin{tabular}{llllll}
\hline $\begin{array}{l}A \\
\left(\mathrm{MPa}^{-\mathrm{n}^{-}(\mathrm{m}+1)}\right)\end{array}$ & $m$ & $n$ & $\beta\left(^{\circ}\right)$ & $\psi\left(^{\circ}\right)$ & $\begin{array}{l}\varepsilon \overline{\sigma_{0}} \\
(\mathrm{MPa})\end{array}$ \\
\hline $3.5410^{-5}$ & -0.593 & 0.716 & $42.9^{\circ}$ & $42.9^{\circ}$ & $10^{-5}$ \\
\hline
\end{tabular}

up to $1200^{\circ} \mathrm{C}$. However, the friction factor is expected to increase with temperature due to the increase in the amount of vitreous phase. The simulations of compression creep tests provided the same results considering a friction factor of 0.6 and a sticky contact. This proves that in this range of friction factor, the simulation is not sensitive to this parameter and provides relevant results.

The last step of the identification procedure involves a comparison of the compression specimen profile, which is computed with the compression creep test simulation for a given dilatation angle, and the profile of a compression specimen, which is measured using an extended field confocal microscope. This comparison shows that the computed curvature of the sample matches the experimental curvature using the assumption of associated flow, i.e., $\psi=\beta$, but is significantly underestimated using the assumption of non-dilatant flow $(\psi=0)$. Therefore, the flow is assumed to be associated, which means that the specimen volume increases while creeping. This calibration procedure, which is applied to the refractory concrete under study at $1200^{\circ} \mathrm{C}$, leads to the values reported in Table 2 for the parameters of the model.

The eccentricity parameter was assumed to be low. A sensitivity analysis was performed to assess the importance of the parameter $\in \cdot \sigma_{0}$. Up to a value of $10^{-2}$, the pseudopotential is almost linear and does not affect the results of the simulations. At $10^{-1}$, the pseudo-potential is not linear, and the model increases the tensile creep rate without affecting the compressive behaviour. This results in the increase of the deflection during the creep bending simulation.

\subsubsection{Results and discussion}

All data provided by the compression tests (time-strain curves and compression specimen curvature) were involved in the calibration procedure and are properly fitted by the model. However, the location of the neutral axis during the bending creep test is the only data provided by the bending test that were involved in the calibration procedure. The bending data that are not used for the calibration purpose (time deflection curve and kinematic full-field measurement) are used to assess the applicability of the model for the material under study. Figure 7 depicts the timedeflection curve that corresponds to the bending creep test and shows that good agreement is obtained while the load remains constant. Therefore, the model satisfactorily reproduces the behaviour of the material under monotonic loads. However, this is not the case under non-monotonic loads, as illustrated by the unloading step (Fig. 7). Indeed, the deflection, which is simulated during unloading, is one-quarter of the value that is measured during the test. 


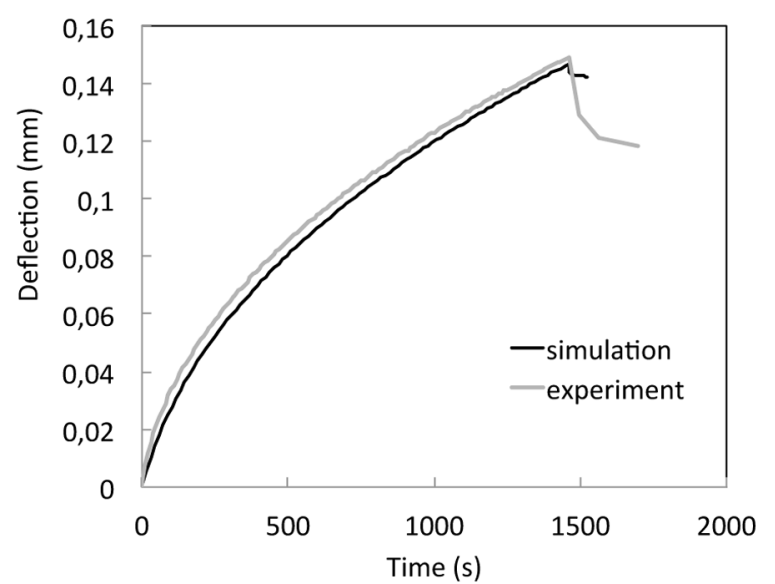

Fig. 7. Simulated and experimental time-deflection curve for the four-point bending creep test (the loading step is not plotted).

This phenomenon is also evidenced by comparing the residual strain field that is obtained through the kinematic full-field measurement and the one computed using the bending test simulation, which provides a strain value that is twice as high as the experimental one, even if the neutral axis is properly located.

The applicability of the Drucker-Prager creep model used in this work to describe the behaviour of the refractory concrete under study is therefore restricted to monotonic loads. Indeed, if the bending specimen is subjected to a second loading step after creeping and unloading, it will exhibit a pronounced non-linear behaviour that is not reproduced by the model, which directly predicts a linear time-deflection curve from the beginning of the second creeping step. Further work includes the assessment of a kinematic hardening to enlarge the applicability of the model to non-monotonic loads.

\subsection{High-temperature measurements of macroscopic deformation induced by phase changes}

Volume expansion induced by phase changes has been studied for a long time in ceramic, composite and civil engineering fields. Classic dilatometers are routinely used and, due to their high accuracy, allow the coefficient of thermal expansion, shrinkage induced by sintering, glassing transition, and chemical changes to be determined. Contactless optical instruments have pushed the temperature limit back and therefore can be used to melt samples during the measurement $[20,21]$. However, the sample size limitation of a few millimetres makes tests difficult on very heterogeneous materials that are made of aggregates of a few millimetres and, therefore, require large representative volumes. The current work aims to determine, at high temperature, the macroscopic change in volume of a heterogeneous sample composed of aggregates of few millimetres that are induced by its own phase changes or in contact with molten oxides and relating the deformation to the phase transformations. A high-temperature furnace has been equipped with a wide quartz window and a highresolution camera to achieve these objectives. Image processing allowed evaluation of the change in diameter

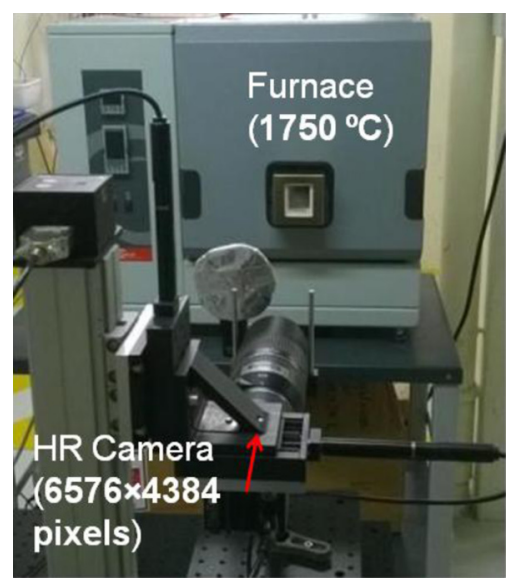

Fig. 8. High-temperature furnace with a high-resolution camera.

over the height of a cylindrical sample. X-ray diffraction and scanning electron microscopy analyses were performed on the samples after the tests to determine the phase changes. This approach was applied to samples that are made of coarse aggregates of bauxite. Comparison of the results from tests without and with pellets of oxides put on the top of the sample allowed to study the effect of the reactive impregnation.

\subsubsection{Experimental development for image acquisition up to $1450^{\circ} \mathrm{C}$}

The device is composed of a high-temperature furnace with a window $\left(40 \times 50 \mathrm{~mm}^{2}\right)$ integrated in the door (Fig. 8) and a high-resolution CCD monochromatic camera $(6579 \times 4384$ pixels $)$ associated with a $70-300 \mathrm{~mm}$ objective. The optical system was calibrated with a gauge block of $30 \mathrm{~mm}$ for each test. The pixel size was evaluated at $12 \pm 1 \mu \mathrm{m}$, depending on the position of the sample and the optical adjustment. The cylindrical samples $(\mathrm{h} \in[30-40] \mathrm{mm}$, $\varnothing \in[25-40] \mathrm{mm}$ ) were placed on two alumina rods (Fig. 9). The sample temperature was evaluated via a thermocouple placed right behind the sample. The sample was heated to $1450{ }^{\circ} \mathrm{C}$ during $4 \mathrm{~h}$ under air with a heating rate of $300^{\circ} \mathrm{C} / \mathrm{h}$. The camera was controlled via a dedicated LabView control interface. After the experiment, the diameter of the sample was evaluated for each picture via image processing using a Labview IMAQ Vision Edge Tool. The vertical position of the sample was determined by the edges of a vertical segment (red vertical line in Fig. 9). Horizontal lines were uniformly distributed over the sample height, and the diameter was evaluated for each horizontal line. An equivalent profile can also be derived from the relative change in diameter.

\subsubsection{Macroscopic swelling of bauxite-based material induced by molten slag}

Bauxite-based samples (Tab. 3) were composed of red bauxite aggregates $(\varnothing \leq 4 \mathrm{~mm})$ mixed with a mineral binder. The binder was composed of 2 lime-alumina phases, $\mathrm{C}(\mathrm{AF})\left\{\mathrm{CaO}-\left(\mathrm{Al}_{2} \mathrm{O}_{3} ; \mathrm{Fe}_{2} \mathrm{O}_{3}\right)\right\}$ and $\mathrm{C}_{2}(\mathrm{AF})\left\{2 \mathrm{CaO}-\left(\mathrm{Al}_{2} \mathrm{O}_{3}\right.\right.$; $\left.\left.\mathrm{Fe}_{2} \mathrm{O}_{3}\right)\right\}$, and gehlenite $\mathrm{C}_{2} \mathrm{AS}\left\{2 \mathrm{CaO}-\mathrm{Al}_{2} \mathrm{O}_{3}-2 \mathrm{SiO}_{2}\right\}$. The 


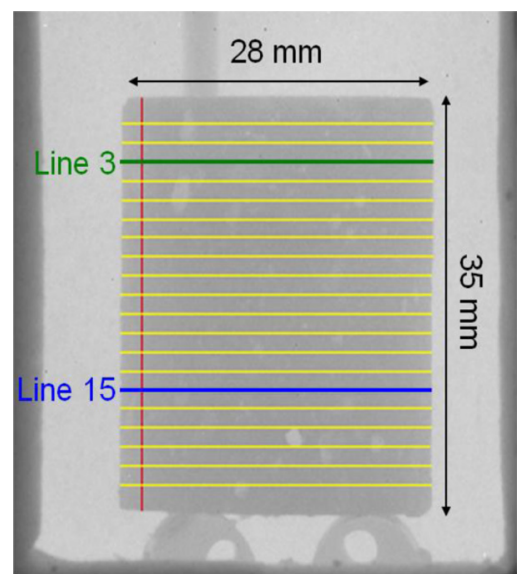

Fig. 9. Bauxite-based cylindrical sample put on alumina rods at high temperature.

Table 3. Chemical composition of bauxite material and reactive molten oxide $( \pm 1 \mathrm{wt} . \%)$.

\begin{tabular}{llllll}
\hline & $\mathrm{Al}_{2} \mathrm{O}_{3}$ & $\mathrm{Fe}_{2} \mathrm{O}_{3}$ & $\mathrm{CaO}$ & $\mathrm{SiO}_{2}$ & $\mathrm{TiO}_{2}$ \\
\hline Bauxite material & 56 & 21 & 12 & 9 & 2 \\
Molten oxides & 40 & 14 & 38 & 6 & 2 \\
\hline
\end{tabular}

cylindrical samples with a $35 \mathrm{~mm}$ height and a $28 \mathrm{~mm}$ diameter were shaped via uniaxial compaction under the $16 \mathrm{MPa}$ pressure and pre-fired at $500^{\circ} \mathrm{C}$. The open porosity was measured via Archimedes' method with oil and ranged from 31 to $35 \%$. The mixture of molten oxides, which is mainly composed of $\mathrm{Al}_{2} \mathrm{O}_{3}, \mathrm{CaO}$ and $\mathrm{Fe}_{2} \mathrm{O}_{3}$ (Tab. 3), was compacted at room temperature to form pellets which were laid on the bauxite samples. The liquidus temperature, $1385^{\circ} \mathrm{C}$, and the solidus temperature, $1140{ }^{\circ} \mathrm{C}$, were determined via differential scanning calorimetry.

The analysis of the change in diameter during the test showed that the material behaviour can be split into 5 stages (Fig. 10):

- RT $-1150{ }^{\circ} \mathrm{C}$ : thermal expansion with a slight decrease of the slope from $800^{\circ} \mathrm{C}$ due to decarbonation;

- $1150-1380^{\circ} \mathrm{C}$ : significant shrinkage due to reactive sintering reactions between bauxite aggregates and the melting secondary phases and mineral binder. The shrinkage due to reactive sintering is higher than the thermal expansion;

- $1380-1450^{\circ} \mathrm{C}$ : melting of the oxides pellets and reactive impregnation into the porous space of the material. Nonuniform swelling of the sample due to precipitation of the expansive phases $\mathrm{C}(\mathrm{AF})_{6}$ and $\mathrm{C}(\mathrm{AF})_{2}$;

- $1450^{\circ} \mathrm{C}-\mathrm{RT}$ : slight increase of the diameter at the beginning of cooling due to the solidification of the liquid phase.

Micrographs of the sample allowed to understand the reactive impregnation that occurred during the test (Fig. 11). The texture of the sample is completely transformed in zone 1. Specifically, aggregates are

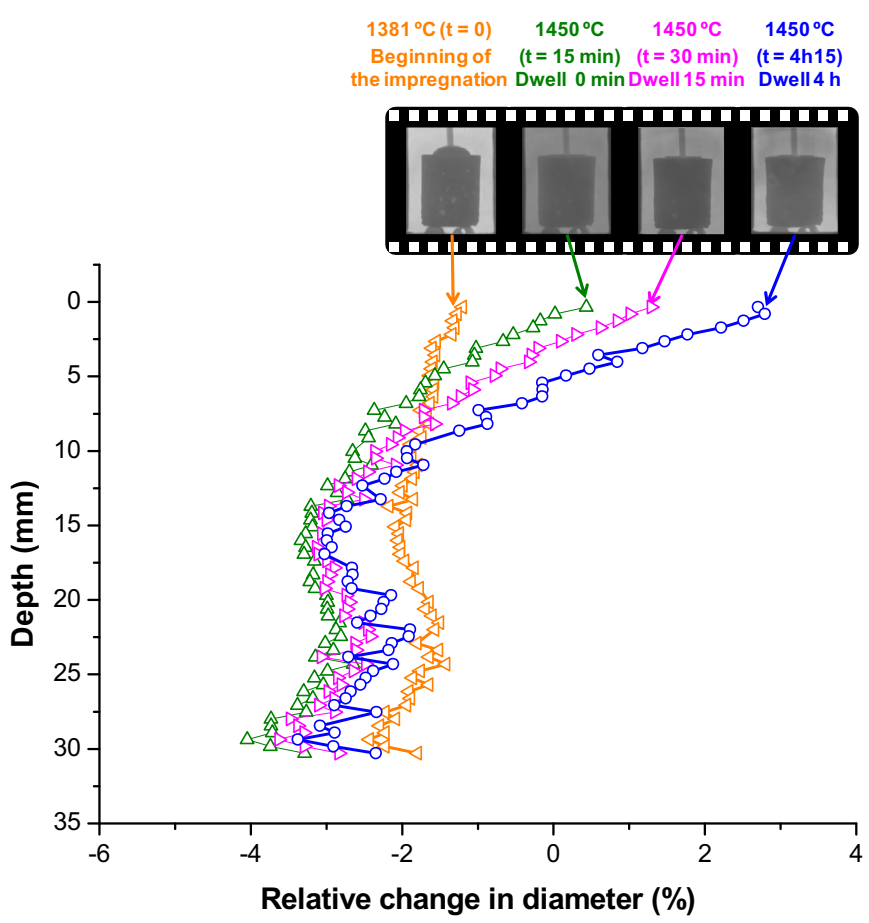

Fig. 10. Evolution of macroscopic deformation during the firing.

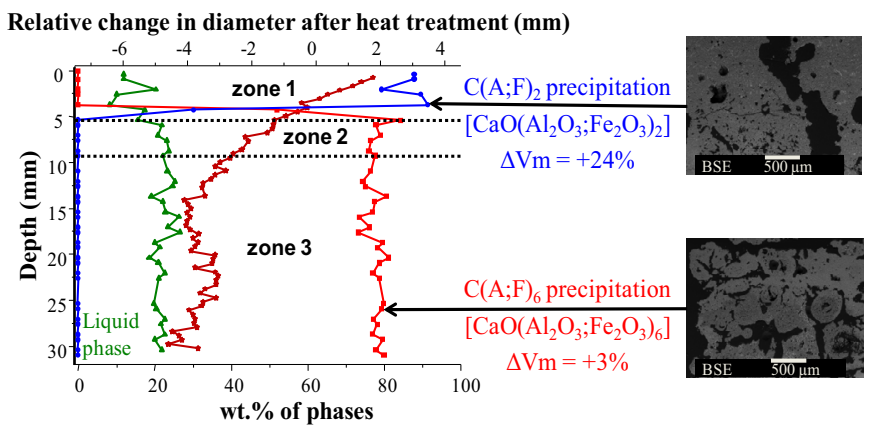

Fig. 11. Phase composition of the sample along the vertical axis after firing according to the Factsage ${ }^{\circledR} 7.1$ thermodynamic calculation from the MEB/EDX mapping.

dissolved, the pore size has significantly increased, and cracks are formed. EDX analyses combined with thermodynamic calculations indicate the precipitation of a $\mathrm{C}(\mathrm{A}$; F) $)_{2}$ solid phase at $1450^{\circ} \mathrm{C}$ and a liquid phase, whose chemical composition was similar to that of $\mathrm{CAS}_{2}$ with a low quantity of $\mathrm{Fe}_{2} \mathrm{O}_{3}(8 \pm 1$ wt.\%). In zones 2 and 3, the texture and microstructure of the sample were similar to the ones of the sample tested alone. $\mathrm{C}(\mathrm{A} ; \mathrm{F})_{6}$ and liquid phase were observed as expected. The sharp change in composition between zone 2 and zone 1 indicates that the interaction between the molten oxides and the sample is differed from zone 2 . Reacting with aggregates, the liquid phase changed in composition, and its reactivity decreased. The mixture of oxides was mainly composed of $\mathrm{Al}_{2} \mathrm{O}_{3}$ and $\mathrm{CaO}$ with a ratio that is very close to the eutectic point that reacts with the alumina aggregates according to a dissolution/precipitation process that forms mono mineral layers of calcium aluminates around the alumina grain 


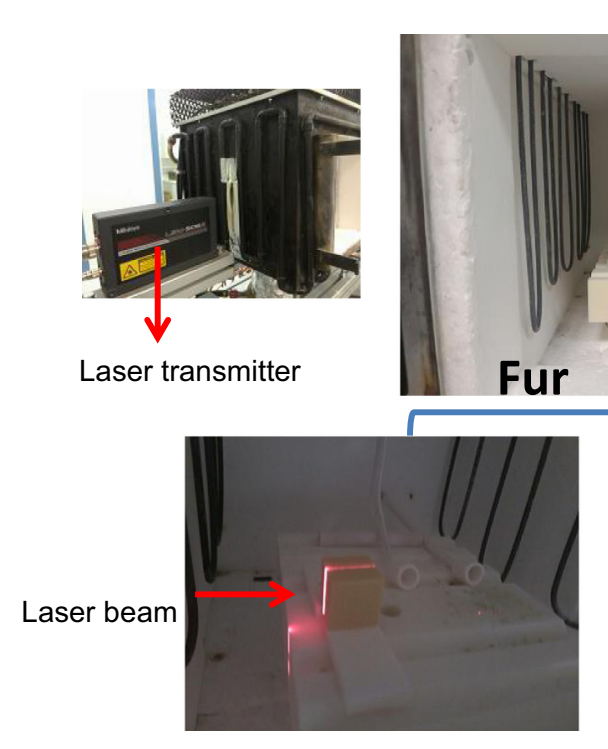

Stress-free thermal dilatation
High temperature optical filter

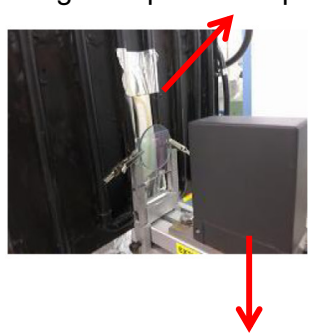

Laser receiver

Fig. 12. Stress-free thermal dilatation measurements and bending test using a laser beam.

(liquid/CA $\left./ \mathrm{CA}_{2} / \mathrm{CA}_{6} / \mathrm{Al}_{2} \mathrm{O}_{3}\right)$ [22]. $\mathrm{C}(\mathrm{A} ; \mathrm{F})_{6}$ precipitated where the liquid phase amount was small in zone 3 and where the reactivity of the liquid has decreased in zone 2 .

According to the calculation from the volumetric lattice parameter of the involved oxide $\mathrm{C}(\mathrm{AF})_{6}$, precipitation leads to a macroscopic expansion of $3 \%$ when precipitation of $\mathrm{C}(\mathrm{AF})_{2}$ expands the volume by approximately $24 \%$. This explains the difference in diameter change between zone 1 and the rest of the sample. The intermediate zone 2 corresponds to the junction between zone 1, with a high content of $\mathrm{C}(\mathrm{AF})_{2}$ and large expansion, and zone 3 , with a high content of $\mathrm{C}(\mathrm{AF})_{6}$ and lower expansion. The gradient of diameter in zone 2 can be explained by elastic strain induced by the difference between zone 1 and zone 3 . Zone 2 plays a role of an accommodation zone for strains that are facilitated by the presence of liquid phase.

The next step of this optical measurement will be reverse identification to identify the chemical expansion(s) parameter(s) for a thermo-chemo-mechanical model such as the one already developed to study the impact of $\mathrm{SiC}$ oxidation in SiC-based refractory [23]. Then, it becomes reasonable to use these results to help the optimization of design of refractory lining [24].

\section{Contribution of modelling for the interpretation of lab tests}

The mechanical characterization of refractory often provides complex results because of the strong evolution of the material with temperature and time. In such cases, whatever the measurement devices are, it is necessary to have a fully thermo-chemo-mechanical model to be able to really understand and use the results. Indeed, too often, a model that is too simple (purely elastic, expansion only dependent on temperature, etc.) leads to erroneous predictions. The example, which has been chosen to illustrate the necessary contribution of modelling for the interpretation of lab tests, concerns the mechanical characterization of fused cast refractories, which are subjected to strong mechanical effects of the tetragonal to monoclinic transformation of zirconia.

Fused-cast refractories are used for glass production. A mixture that belongs to the silica-alumina-zirconia system is fused in an arc furnace and cast in moulds. After machining, these blocks are assembled together to constitute the glass furnace. During the cooling of the blocks, several thermal (solidification or phase transformation enthalpies) or mechanical (creep, stiffening, and phase transformation) effects affect the material. Some fused-cast refractories contain a large amount of zirconia that is not stabilized and hence endures the martensitic transformation from tetragonal to monoclinic during cooling at approximately $1000^{\circ} \mathrm{C}$. Contrary to sintered zirconia, the interlacing of zirconia dendrites allows the associated volume increase of more than $4 \%$ to be accommodated, without microstructure collapsing. This part constitutes a short summary of more than 10 years of research on this topic and focuses on the thermal and mechanical effects induced by this phase transformation on the refractory.

Mechanical tests have been performed according to a thermal cycle as close as possible to the actual cooling procedure. The specimens were first heated and maintained at $1500^{\circ} \mathrm{C}$ for 1 hour to recover the original microstructure as much as possible and relax the residual stresses [25-27]. From this temperature, the specimens were cooled, and the transformation occurred at $9^{\circ} \mathrm{C} / \mathrm{h}$, which corresponds to industrial cooling conditions. The first effect that has been characterized is the swelling induced by the phase transformation. The measurements of linear elongation using a laser beam (Fig. 12) (i.e., without any load applied to the specimen) in the three characteristic directions of the block revealed that the linear expansion of approximately $2 \%$ is isotropic and ranges approximately between 1020 and $880^{\circ} \mathrm{C}$. 
a)
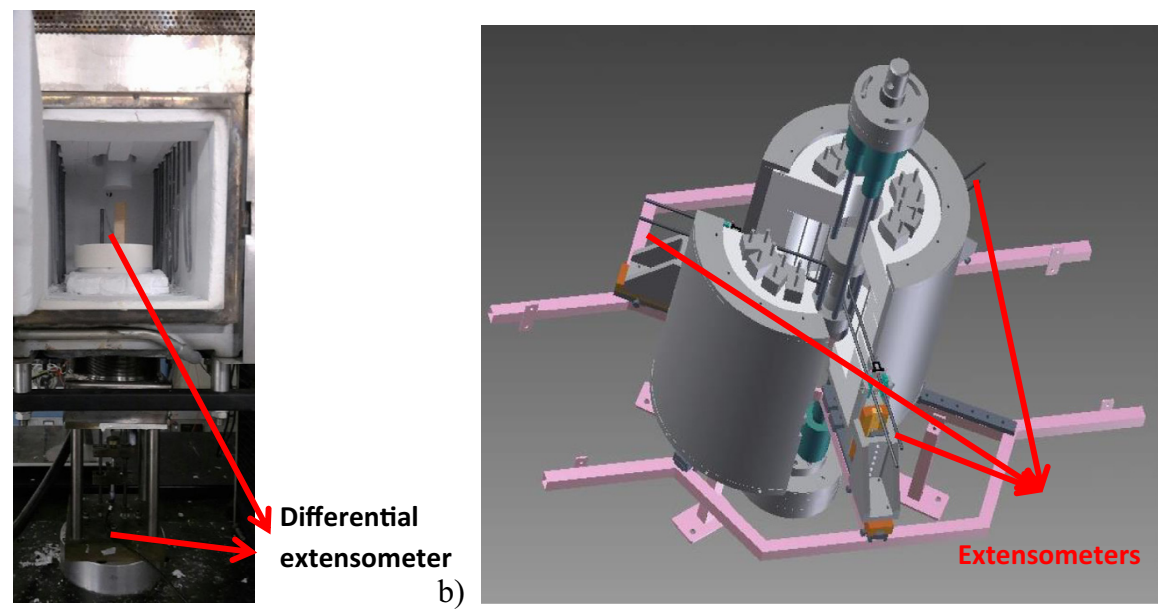

Fig. 13. (a) Compression test using a differential extensometer, (b) Tensile test.

To reveal the influence of an external stress, similar tests have been performed with a constant tensile or compressive stress applied from $1300^{\circ} \mathrm{C}$ to RT during the transformation (Fig. 13). For both types of tests, the specimen volume was isothermal ("hot" gripping was used for the inversed tensile test) [28], which is of prime importance because of the significant sensitivity of transformation advancement on temperature. The specimen longitudinal and transverse elongations were measured via mechanical extensometers.

Compression tends to decrease the expansion of the material. Even the stress levels as low as $-0.1 \mathrm{MPa}$ have a significant influence. The higher the compression level was, the higher was the expansion reduction. For the highest stress level $(-20 \mathrm{MPa})$, the shortening of the specimen can be observed. In some tests, constant temperature was maintained inside the phase transformation interval. During these plateaus, with or without the applied stress, the deformation remained constant. This observation proved that the temperature level controls the swelling as well as the plastic deformation of the material within the transformation interval. The same type of results was observed in an inverse way for tension, with an enhanced effect of stress. During a descent ramp at $9^{\circ} \mathrm{C} / \mathrm{h}$ between 1050 and $850^{\circ} \mathrm{C}$, the length of the specimen remained constant. Then, the dilation of the specimen in this direction was accommodated by the plastic flow. A nonlinear increase of the compressive stress, which is induced by the inhibition of deformation, was then observed.

From these experimental observations, three different characteristics must be introduced in the model to describe the observed mechanical behaviour:

- a volume swelling of the material depending on applied stress;

- a plastic flow is different under tension and compression, activated even for very low stress levels (low elastic limit); - a temperature control of both observed phenomena.

To consider all these characteristics, Leblond's type model [29] has been extended by introducing a Cam-clay yield function without consolidation. In this model, the progress of zirconia transformation is controlled by the

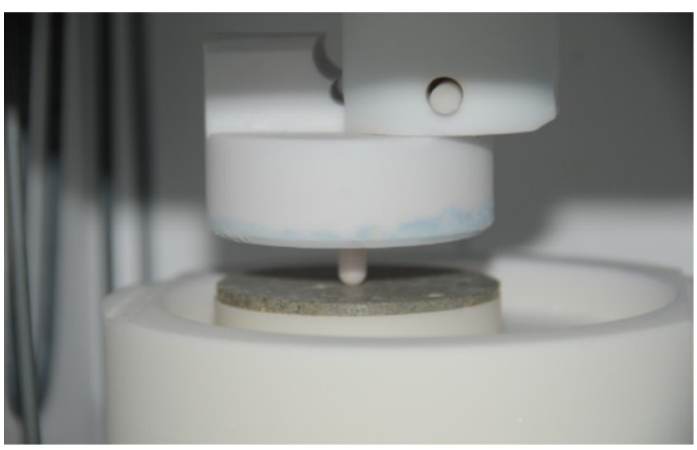

Fig. 14. Ball-to-ring test.

evolution of the temperature. The numerical values of the three most relevant parameters involved in this model were optimized to fit the experimental results. The model was finally validated by the comparison of its predictions with experimental results that are issued from different mechanical tests. During cooling within the phase transformation interval, the model provides a satisfying description of the swelling and deflection of a beam submitted to 3-point bending (Fig. 13) (non-uniform stresses) and of the deflection of a disk loaded under ball-toring test conditions (Fig. 14). This validated model was complemented by other components of the mechanical behaviour (creep, elasticity, etc.). It is now used by the Saint Gobain Company to improve the process of existing materials (processing time, quality, etc.) and to optimize the process of innovating materials by considering their specific thermomechanical properties.

\section{New in situ instrumentations and spectroscopies to study high temperature phase transformations and corrosion in refractories}

Phase transformations and the microstructural evolution of refractories in a severe environment (high temperature, 


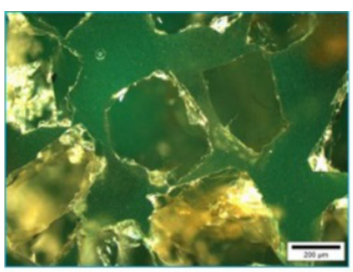

$20^{\circ} \mathrm{C}$

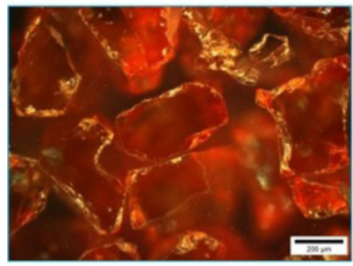

$1000^{\circ} \mathrm{C}$

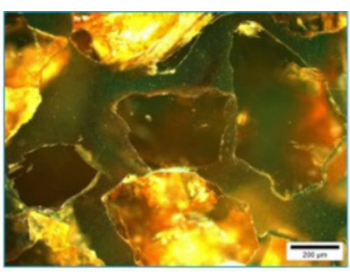

$600^{\circ} \mathrm{C}$

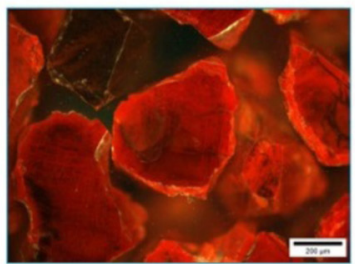

$1200^{\circ} \mathrm{C}$

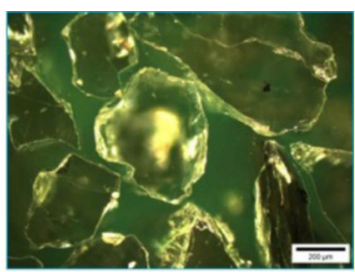

$800^{\circ} \mathrm{C}$

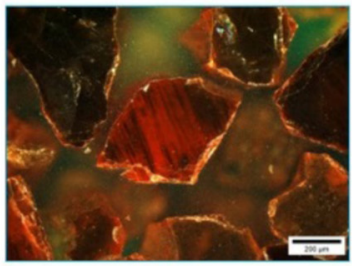

$1400^{\circ} \mathrm{C}$

Fig. 15. Colour evolution of olivine grains with temperature.

corrosion in contact with slag or gas, and mechanical stresses) are key points of their performance [30]. Significant progress has been made: combining different efficient laboratory techniques with digital processing of data provides information (e.g., degradation mechanisms) that cannot be obtained directly. Recent experimental developments to characterize thermochemical interactions of service behaviour, transformations of refractories and kinetic of reactions are described below. The potentialities of these techniques are illustrated by some examples: evolution of mineral phases and reactivity of olivine-based refractories, corrosion kinetics of high alumina refractories by molten oxides (slag).

\subsection{Application of Raman spectroscopy and in situ high temperature $\mathrm{X}$-ray diffraction to phase transformations of olivine}

This example is focused on the interest and applicability of two powerful techniques: Raman spectroscopy, particularly in its mapping mode, and in situ high-temperature X-ray diffraction [31,32].

The chemical and phase characterizations were performed via Raman spectroscopy (InVia Reflex Renishaw) using a $633 \mathrm{~nm}$ laser wavelength at $13 \mathrm{~mW}$ (laser output). Individual spectra were collected under a microscope (100× objective), with Raman-scattered light dispersed by a holographic grating of 1800 grooves $/ \mathrm{mm}$ and detected by a charge coupled device (CCD) camera. Raman mappings were performed using two different objectives $(\times 20$ and $\times 100)$ and a holographic grating of 600 grooves $/ \mathrm{mm}$.

Olivine, $(\mathrm{Mg}, \mathrm{Fe})_{2} \mathrm{SiO}_{4}$, is a refractory material that is composed of a solid solution of magnesium silicate (forsterite $\mathrm{Mg}_{2} \mathrm{SiO}_{4}$ ) and iron silicate (fayalite $\mathrm{Fe}_{2} \mathrm{SiO}_{4}$ ). Olivine is used in different refractory applications. For instance, it is used in tundish linings for steelmaking. It is also used as bed materials in fluidized reactors of gasification to produce a $\mathrm{CO}+\mathrm{H}_{2}$ high calorific synthesis gas [33]. Olivine is not an inert magnesium silicate, and the resulting phase transformations are not well understood. It

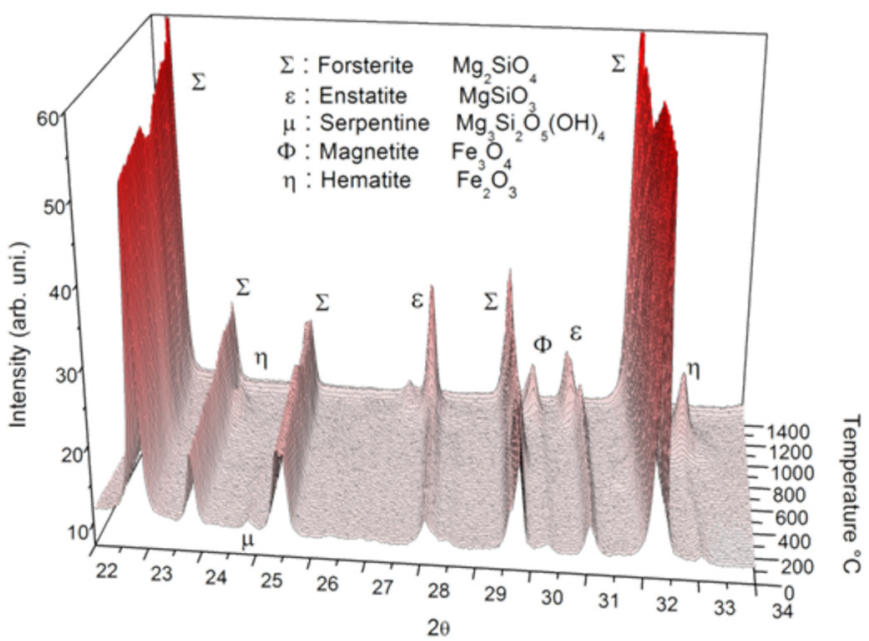

Fig. 16. In situ HT-XRD of olivine.

transforms via thermal decomposition. The green colour of olivine grains changes to red with a temperature increase (Fig. 15), and the resulting phase transformations are complex.

Figure 16 illustrates the insitu HT-XRD data of olivine. The hydrated serpentine phase disappears at approximately $600{ }^{\circ} \mathrm{C}$. Both forsterite and enstatite phases seem to be formed after the heat treatment of olivine in air according to the following chemical equation (Eq. (7)).

$$
2 \mathrm{Mg}_{3} \mathrm{Si}_{2} \mathrm{O}_{5}(\mathrm{OH})_{4} \rightarrow 2 \mathrm{Mg}_{2} \mathrm{SiO}_{4}+2 \mathrm{MgSiO}_{3}+4 \mathrm{H}_{2} \mathrm{O} .
$$

New phases are formed, as seen by the $2 \theta=23.8^{\circ}$ and $32.7^{\circ}$ peaks between 960 and $1200^{\circ} \mathrm{C}$ and the $2 \theta=29.7^{\circ}$ peaks between 1185 and $1368^{\circ} \mathrm{C}$. According to the literature, these phases are identified as haematite (8) and magnetite (9) or magnesio-ferrite $\left[\mathrm{MgFe}_{2} \mathrm{O}_{4}\right]$ but also form a solid solution such as $\mathrm{MgFe}_{2} \mathrm{O}_{4}-\mathrm{Fe}_{3} \mathrm{O}_{4}$ and/or $\mathrm{MgFe}_{2} \mathrm{O}_{4}-\alpha-\mathrm{Fe}_{2} \mathrm{O}_{3}$. XRD 
was not able to determine the type of iron oxide phases due to its peak resolution and peak overlapping of phases in olivine.

$$
\begin{aligned}
& 2 \mathrm{Fe}_{2} \mathrm{SiO}_{4}+\mathrm{O}_{2} \rightarrow 2 \mathrm{Fe}_{2} \mathrm{O}_{3}+2 \mathrm{SiO}_{2}, \\
& 3 \mathrm{Fe}_{2} \mathrm{SiO}_{4}+\mathrm{O}_{2} \rightarrow 2 \mathrm{Fe}_{2} \mathrm{O}_{4}+3 \mathrm{SiO}_{2} .
\end{aligned}
$$

Then, silica reacts with forsterite to form enstatite according to reaction (10).

$$
\mathrm{Mg}_{2} \mathrm{SiO}_{4}+\mathrm{SiO}_{2} \rightarrow 2 \mathrm{MgSiO}_{3} .
$$

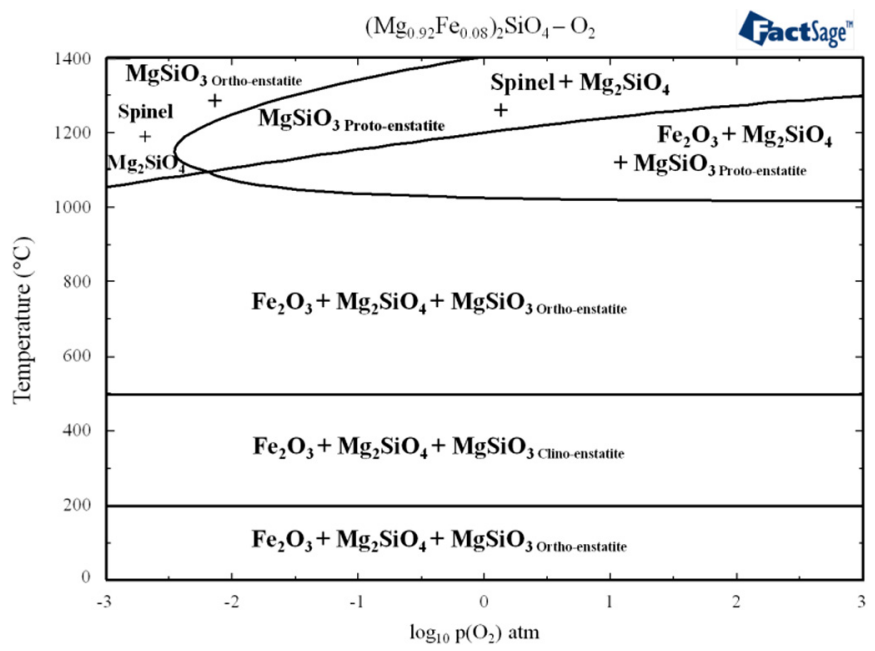

Fig. 17. Phase diagram of $\left(\mathrm{Mg}_{0.92} \mathrm{Fe}_{0.08}\right)_{2} \mathrm{SiO}_{4}-\mathrm{O}_{2}$, Factsage v6.2.
The phase transformation of ortho-enstatite into protoenstatite was observed at $1100^{\circ} \mathrm{C}$, mainly at $2 \theta=31^{\circ}$. The phase diagram, determined by thermodynamic modelling (Fig. 17) confirms the experimental data of enstatite observed at high temperature.

Iron oxide phases were successfully identified via Raman spectroscopy. Figure 18 presents the reflected light micrograph on the calcined olivine at $1400^{\circ} \mathrm{C}$. A simple visual inspection of these images shows a heterogeneous structure that is composed of dark and bright areas. The dark areas appear in the form of veins. Hematite and magnetite phases have shown to be heterogeneously distributed within olivine material, as assessed using Raman mapping.

Figure 19 displays the micrograph of three calcined olivine particles sintered at $1400^{\circ} \mathrm{C}$ for $48 \mathrm{~h}$. From this micrograph, a Raman mapping was performed. Raman spectra are sequentially collected, point by point, over a defined region. Then, the maps are reconstructed by a linear combination of spectra from the three pure components contained in the sample (Fig. 20).

Four phases were detected using Raman mapping. Forsterite is found in three olivine particles with hematite, which gives the red colour on the optical micrograph. Magnetite and enstatite are found after sintering. Magnetite is also detected on the olivine particle surface.

In summary, olivine transforms at high temperature by dehydration below $600^{\circ} \mathrm{C}$ and oxidation of fayalite, at first in haematite $\left(960^{\circ} \mathrm{C}\right)$ and gradually in magnetite $\left(1200^{\circ} \mathrm{C}\right)$. Enstatite and magnetite diffuse from the inner part of the olivine grain to the surface, forming a layer and causing the sintering between particles after approximately $1200^{\circ} \mathrm{C}$.
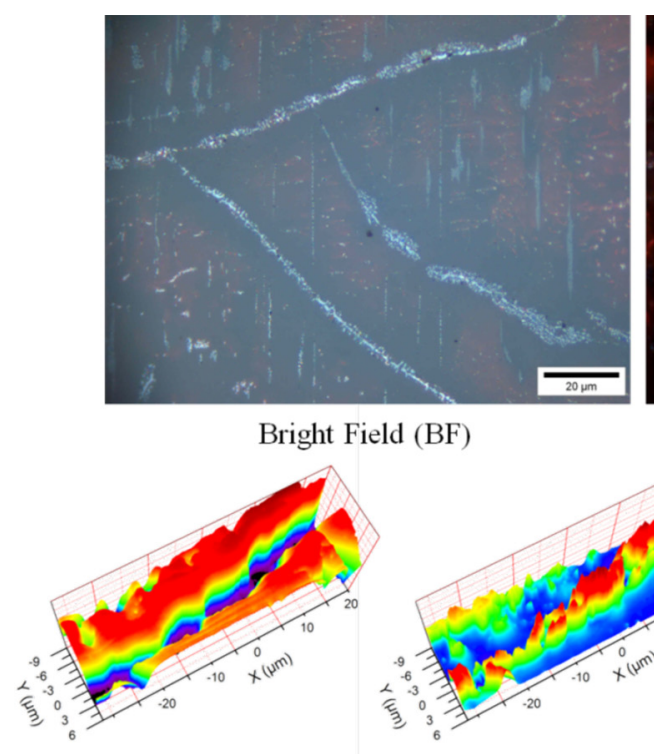

(a)

(b)

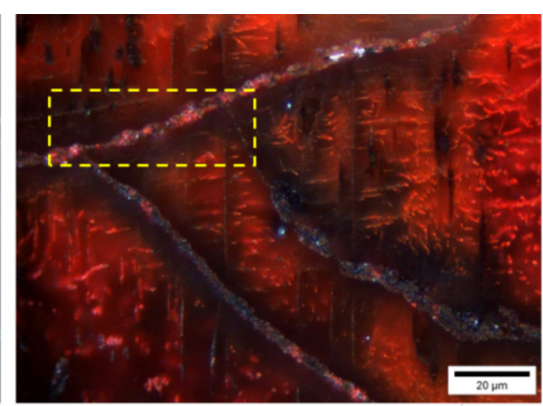

Dark field (DF)

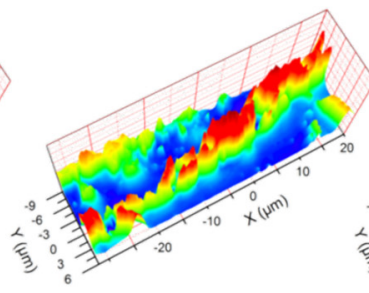

Magnetite

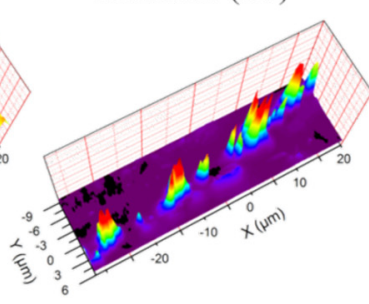

(c)

Forsterite

Fig. 18. Analysed zone of calcined olivine at $1400^{\circ} \mathrm{C}$ in Raman mapping at high resolution: score maps of forsterite (a), magnetite (b) and haematite (c). 


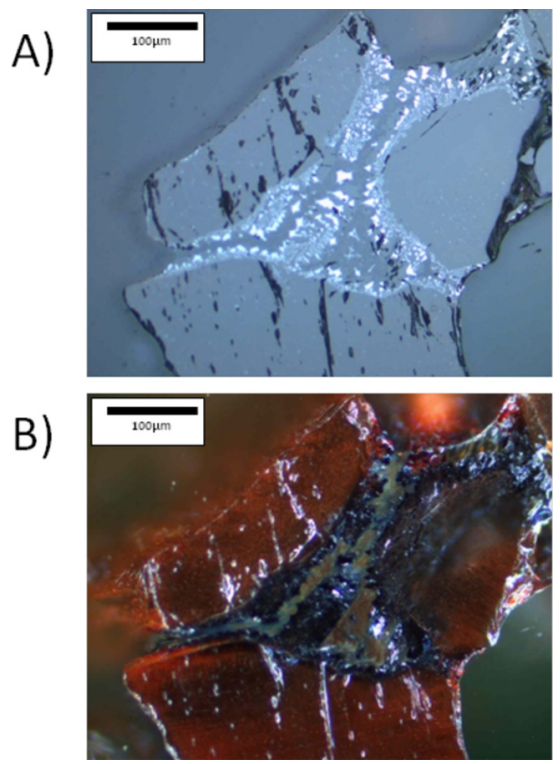

Fig. 19. Micrograph of calcined olivine at $1400^{\circ} \mathrm{C}-48 \mathrm{~h}$. (A) Bright field, (B) Dark field.

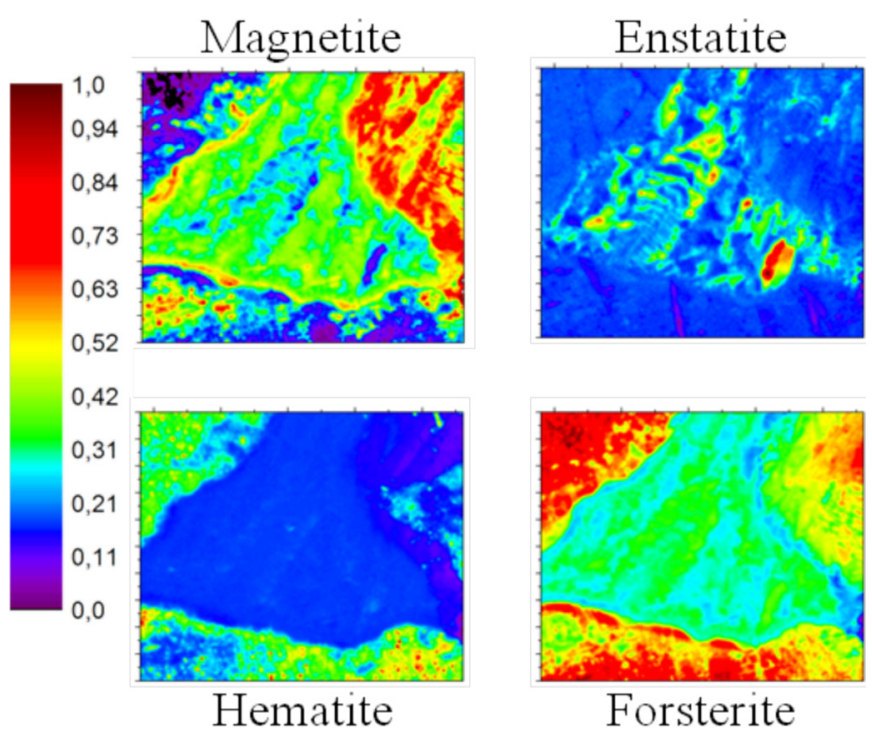

Fig. 20. Raman mapping of calcined olivine sintering.

\subsection{Application of time-resolved in situ high temperature $\mathrm{X}$-ray diffraction to corrosion kinetics of high alumina refractories}

The kinetics of corrosion are important data for the thermo-chemo-mechanical modelling of the behaviour of refractory to realize predictive computation of long-term service [22,34]. This work aims to quantify the timedependent corrosion of high alumina refractories by slag. The objective was to determine corrosion kinetics based on time-resolved X-ray diffraction at high temperature combined with Rietveld quantification.

A high-temperature strip heater chamber (HTK16 Anton Paar) was used for in situ XRD studies of phase formation. The corrosion tests were performed on an INEL

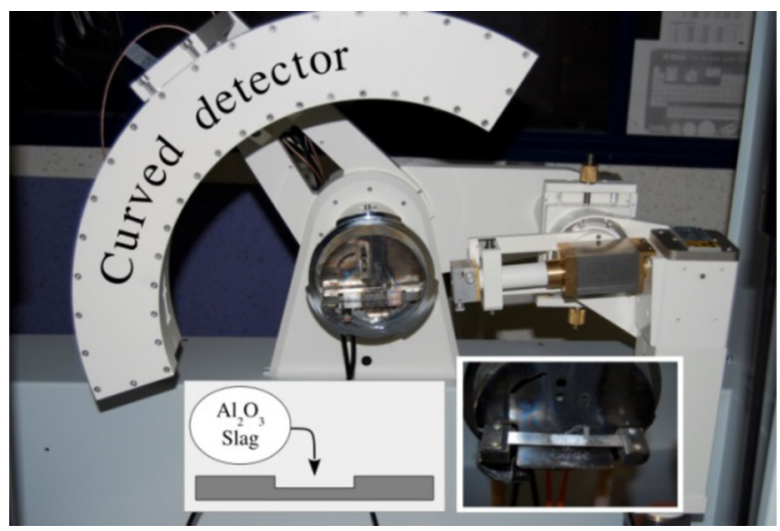

Fig. 21. In situ corrosion test using high temperature XRD.

CPS120-equiped powder diffractometer (Equinox 3000, INEL) set up in a horizontal Debye-Scherrer geometry in reflexion mode with the following conditions (Fig. 21). The angle of the incident X-ray beam was adjusted to $15^{\circ}$ with respect to the sample surface. The counting time was kept constant at $5 \mathrm{~s}$ per step.

The mixture of slag and alumina refractory powders was applied directly to the platinum heating strip. The heat treatment consisted of three stages:

- heating at $5{ }^{\circ} \mathrm{C} / \mathrm{s}$. No compacting the batch and maximum temperature rate enabled to avoid reaction between the refractory powder and the ground slag in solid state before the melting of the slag;

- dwell for 15 minutes at $1600^{\circ} \mathrm{C}$;

- cooling at $5{ }^{\circ} \mathrm{C} / \mathrm{s}$.

Approximately 300 diffraction patterns were recorded during the corrosion test. The Rietveld analysis program Maud was used for the Rietveld refinement in this study [35].

As an example, Figure 22 shows the XRD quantification carried out for the mixture composed of $85 \mathrm{wt} . \%$ alumina with $15 \mathrm{wt} . \%$ binary slag composed of $45 \mathrm{wt} . \%$ $\mathrm{CaO}+45$ wt. $\% \mathrm{Al}_{2} \mathrm{O}_{3}$. The expected equilibrium phases are $\mathrm{Al}_{2} \mathrm{O}_{3}\left(11\right.$ wt. \%) and $\mathrm{CA}_{6}(89$ wt. \%). The plot starts when the dwell temperature has been reached $\left(1600^{\circ} \mathrm{C}\right)$, i.e., after the heating stage. It can be observed that half of the alumina was dissolved after 5 minutes, and its dissolution had stopped after 10 minutes, which is in agreement with ex situ results. $\mathrm{CA}_{6}$, which is the main precipitating phase, increases with a similar rate. The slag amount decreased very quickly as well. For every quantification, the remaining slag is calculated by assuming that its composition does not change $(50 \mathrm{wt} . \%$ $\mathrm{CaO}+50$ wt. $\% \mathrm{Al}_{2} \mathrm{O}_{3}$ ), although its actual alumina content increases the solubility limit to form $\mathrm{CA}_{2}$. Therefore, it is not clear that slag remained after 5 minutes (less than 5 wt.\%). The amount of remaining slag may be added to the amount of $\mathrm{CA}_{2}$. This possible difference does not change the weight fraction of the stable phases $\mathrm{Al}_{2} \mathrm{O}_{3}$ and $\mathrm{CA}_{6}$.

To sum up, the results show that the corrosion process is very fast and involves an indirect dissolution mechanism. The insitu experiments, which are based on high temperature X-ray diffraction, allowed for the study of the reactions during the very beginning of corrosion. This 


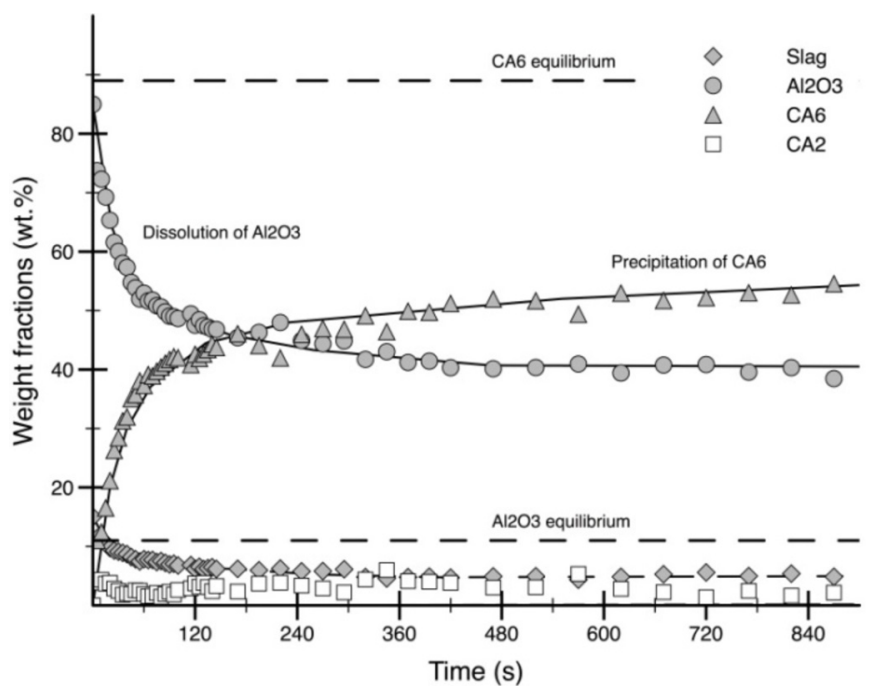

Fig. 22. Kinetics curves of insitu corrosion test. $\mathrm{Al}_{2} \mathrm{O}_{3}$ refractory $/ 50$ wt. $\% \mathrm{Al}_{2} \mathrm{O}_{3}-50$ wt. $\% \mathrm{CaO}$ slag $-1600^{\circ} \mathrm{C}$.

technique also allowed to show the key role of slag and to explain the difference of behaviour according to the slag composition and refractory/slag ratio.

\section{Conclusion}

Four major poles describe the degradation of the refractories, i.e., "thermal-mechanical-transfer of matterphase changes", which are connected by more or less strong couplings. The analysis of these couplings makes it possible to select the most appropriate experimental and numerical techniques. Research on the in-use behaviour of refractories increasingly uses the methods that combine complementary experimental and numerical analyses, involving phenomena of varied origin, to identify the causes of deterioration and the thermomechanical and thermochemical evolutions. These laboratory techniques take into account the material behaviour of the micrometric scale up to the macroscopic scale.

The development of optical measurement at high temperature, which is based on digital image correlation, coupled with numerical computations and reverse identification, allows for the refinement of the characterization of mechanical behaviour of the refractory. As shown in the examples of this article, it becomes possible to obtain a good representation of complex laws, including asymmetry between tension/compression and inelastic behaviour. These new techniques allow the "chemically" induced strain to be studied and then account for such phenomenon in the mechanical behaviour.

The keystone of the refractory lifetime in service is the kinetics of the phase change and/or corrosion and thermochemical evolution of the material, coupled with its thermomechanical load in service. New techniques, such as Raman or XRD with dedicated instrumentation, help in the characterization of the kinetic law of these thermochemical evolutions. Such studies, coupled with the concept and numerical tools that permit to develop the model that takes into account the coupling between thermochemistry and thermo-mechanics, will permit the establishment of a more reliable simulation of in-service behaviour of refractory.

These advanced techniques offer the scientific community that works in the field of refractory materials new opportunities to conduct multidisciplinary studies to improve the knowledge and the prediction of the phenomena of degradation of the refractories. For the user industries, new prospects also emerge due to the development of more efficient refractories, which reduce costs.

Since in situ measurements of the refractory properties are currently possible on a laboratory scale, future challenges include installation of industrial instruments and processes to validate large-scale results.

The authors would like to thank the following: the GFC and SF2M societies for the organization of the refractory colloquium titled "Interprétation et modélisation des essais réfractaires" (in French), June 9, 2016, in Paris; the French National Research Agency (ANR) for funding the research project (ASZTech) and Saint Gobain Company for providing the specimens.

\section{References}

1. P. Boisse, A. Gasser, J. Poirier, J. Rousseau, Compos. Part B: Eng. 32(5), 461 (2001)

2. B.M.B. Grant, H.J. Stone, P.J. Withers, M. Preuss, J. Strain Anal. Eng. Design 44(4), 263 (2009)

3. B. Pan, D. Wu, Z. Wang, Y. Xia, Meas. Sci. Technol. 22(1), $015701(2011)$

4. A. Sutton, C. McFadden, Opt. Lasers Eng. 32(4), 367 (1999)

5. F. Hild, S. Roux, Strain 42, 69 (2006)

6. P. Leplay, J. Réthoré, S. Meille, M.-C. Baietto, J. Eur. Ceram. Soc. 32, 3949 (2012)

7. J. Réthoré, F. Hild, S. Roux, Comput. Methods Appl. Mech. Eng. 196, 5016 (2007)

8. B. Semin, H. Auradou, M. François, Eur. Phys. J. Appl. Phys. 56, 1 (2011)

9. C. Gazeau, J. Gillibert, E. Blond, P.M. Geffroy, N. Richet, J. Eur. Ceram. Soc. 35, 3853 (2015)

10. N.I. Muskhelishvili, Some Basic Problems of the Mathematical Theory of Elasticity, 4th edn. (Noordholl International Publishing, 1954)

11. E. Blond, N. Schmitt, F. Hild, J. Poirier, P. Blumenfeld, J. Eur. Ceram. Soc. 25, 1819 (2005)

12. A.S. Mammar, D. Gruber, H. Harmuth, S. Jin, Ceram. Int. 42(6), 6791 (2016)

13. G. Besnard, F. Hild, S. Roux, Exp. Mech. 46, 789 (2006)

14. P. Leplay, O. Lafforgue, F. Hild, J. Ame. Ceram. Soc. 98(7), $2240(2015)$

15. F. Hild, S. Roux, R. Gras, N. Guerrero, M.E. Marante, J. Florez-Lopez, Opt. Lasers Eng. 47, 495 (2009)

16. P. Leplay, J. Réthoré, S. Meille, M.-C. Baietto, J. Eur. Ceram. Soc. 30(13), 2715 (2010)

17. G. Dusserre, O. Valentin, F. Nazaret, T. Cutard, J. Eur. Ceram. Soc. 36, 2627 (2016)

18. H. Marzagui, T. Cutard, J. Mater. Process. Technol. 155-156, 1474 (2004)

19. G. Dusserre, F. Nazaret, L. Robert, T. Cutard, J. Eur. Ceram. Soc. 33, 221 (2013)

20. J.D. James, J.A. Spittle, S.G.R. Brown, R.W. Evans, Meas. Sci. Technol. 12(3), 1 (2001) 
21. R. Montanini, F. Freni, Meas. Sci. Technol. 25(1), 015013 (2014)

22. E. de Bilbao, M. Dombrowski, J. Poirier, China's Refract. 24, 7 (2015)

23. T. Merzouki, E. Blond, N. Schmitt, M.-L. Bouchetou, T. Cutard, A. Gasser, Mech. Mater. 68, 253 (2014)

24. T. Merzouki, E. Blond, N. Schmitt, Finite Elem. Anal. Des. 108(1), 66 (2016)

25. L. Petroni, M. Boussuge, D. Ryckelynck, J. Eur. Ceram. Soc. 32, 3941 (2012)

26. L. Petroni, Étude du comportement post-coulée de réfractaires électro-fondus à Très Haute Teneur en Zircone (THTZ). Matériaux [physics.med-ph] (École Nationale Supérieure des Mines de Paris, Paris, 2011)

27. Y. Zhang, Étude des conséquences mécaniques de la transformation de phase dans des réfractaires électro-fondus à Très Haute Teneur en Zircone (THTZ). Mécanique [physics.med-ph] (École Nationale Supérieure des Mines de Paris, Paris, 2017)
28. L. Massard, Étude du fluage de réfractaires électro-fondus du système alumine-zircone-silice. Mécanique [physics.med-ph] (École Nationale Supérieure des Mines de Paris, Paris, 2005)

29. J.B. Leblond, G. Mottet, J.C. Devaux, J. Mech. Phys. Solids 34, 411 (1986)

30. J. Poirier, M.L. Bouchetou, F. Qafssaoui, J.P. Ildefonse, J. Eur. Ceram. Soc. 28(8), 1557 (2008)

31. R. Michel, M.R. Ammar, J. Poirier, P. Simon, Ceram. Int. 39, 5287 (2013)

32. R. Michel, M.R. Ammar, E. Veron, P. Simon, J. Poirier, RSC Avances 4, 26645 (2014)

33. R. Michel, J. Kaknics, E. de Bilbao, J. Poirier, Ceram. Int. 42, 2570 (2016)

34. E. de Bilbao, J. Poirier, M. Dombrowski, Metall. Res. Technol. 112(6), 607 (2015)

35. O. Masson, R. Guinebretiere, A. Dauger, J. Appl. Crystallogr. 29(5), 540 (1996)

Cite this article as: Jacques Poirier, Eric Blond, Emmanuel de Bilbao, Rudy Michel, Antoine Coulon, Jean Gillibert, Michel Boussuge, Yang Zhang, David Ryckelynk, Gilles Dusserre, Thierry Cutard, Paul Leplay, New advances in the laboratory characterization of refractories: testing and modelling, Metall. Res. Technol. 114, 610 (2017) 